\title{
Gestão do conhecimento: percepção dos discentes em relação ao ensino de conteúdo contábil
}

\author{
Daniel Berg Rodrigues Barroso ${ }^{1}$, Ronei De Araújo Mimo², Gleimiria Batista da \\ Costa Matos ${ }^{3}$, Marlene Valério Dos Santos Arenas ${ }^{4}$ Vanessa Fernanda Rios De \\ Almeida ${ }^{5}$
}

\begin{abstract}
RESUMO
Esta pesquisa tem como objetivo verificar o nível de compreensão dos discentes dos cursos de Administração e Ciências Econômicas da Fundação Universidade Federal de Rondônia (UNIR) em relação ao conteúdo contábil ensinado no decorrer desses cursos. A pesquisa é classificada como: quantitativa e qualitativa quanto a abordagem do problema e descritiva quanto ao objetivo. Em relação aos procedimentos técnicos utilizados classifica-se como levantamento aplicado por meio de um questionário, aos discentes matriculados no sexto e sétimo período do curso de Administração, e os discentes do quinto e sexto período do curso de Ciências Econômicas. O resultado da pesquisa indica que a maioria dos discentes concordam com a importância dos conteúdos ministrados para sua formação e futuro profissional. A importância das disciplinas de conteúdo contábil e a capacidade de síntese e clareza também foram pontos relevantes. Em relação as questões abertas percebem-se que os discentes deram uma maior importância na assimilação do conteúdo.
\end{abstract}

Palavras-chave: Conteúdo contábil; Gestão do Conhecimento; Percepção.

\begin{abstract}
This research aims to verify the level of understanding of students in the Administration and Economics courses at the Federal University of Rondônia Foundation (UNIR) in relation to the accounting content taught during these courses. The research is classified as: quantitative and qualitative regarding the approach to the problem and descriptive regarding the objective. Regarding the technical procedures used, it is classified as a survey applied through a questionnaire, to students enrolled in the sixth and seventh period of the Administration course, and the students of the fifth and sixth period of the Economic Sciences course. The survey results indicate that most students agree with the importance of the contents taught for their training and professional future. The importance of accounting content disciplines and the capacity
\end{abstract}

$1 \quad$ Universidade Federal de Rondônia. Email: danielbergg19@ gmail.com

$2 \quad$ Universidade Federal de Rondônia. Email: roneimimo78@gmail.com

$3 \quad$ Universidade Federal de Rondônia. Email :gleimiria@unir.br

$4 \quad$ Universidade Federal de Rondônia. Email: marlenearenas@ unir.br

$5 \quad$ Universidade Federal de Rondônia. Email:vanessarios@unir.br 
for synthesis and clarity were also relevant points. Regarding the open questions, it is clear that the students gave greater importance to the assimilation of the content.

Keywords: Accounting content; Knowledge management; Perception.

\section{INTRODUÇÃO}

A gestão do conhecimento surge e é amplamente difundida nas esferas organizacionais e empresariais, tendo como objeto, o conhecimento organizacional. Não obstante, existem outros campos nos quais há uma elevada prática de atividades focadas em conhecimento como, por exemplo, o ambiente acadêmico. As universidades se constituem como um dos principais órgãos de produção do conhecimento científico, sendo um campo fértil para a aplicação e o estudo da gestão do conhecimento.

Em relação à produção de conhecimento acadêmico contábil, pode-se destacar o ensino de práticas contábeis que permitem aos discentes interpretarem informações contábeis. A informação contábil é utilizada nas mais diversas áreas, sendo interpretada por usuários, que se dividem em dois grupos: os internos e externos. Os usuários internos (executivos, gerentes, funcionários em geral) estão intimamente ligados aos objetivos e atividades empresariais; os usuários externos (governo, fornecedores, investidores, sindicatos, discentes), possuem interesse nas informações contábeis, porém, sob outras perspectivas, já que essas pessoas ou órgãos não se encontram, propriamente dentro da entidade ou envolvidos com ela diretamente.

Quanto aos usuários externos, pode-se destacar os estudantes de conteúdos contábeis, como contadores, estatísticos, administradores, economistas e outros, que no decorrer de sua formação científica elaboram, analisam e interpretam diversos tipos de informações contábeis. Nesse contexto, o ensino da contabilidade para os cursos de Administração, Ciências Econômicas, bem como outros cursos relacionados à gestão de negócios, tem a finalidade de proporcionar conhecimento e compreensão das informações contábeis com o intuito de auxiliar a gestão, a tomada de decisão e, ainda durante a graduação, preparar os discentes para outras disciplinas do curso (ETTER; BURMEISTER; ELDER, 2000).

Hernandes, Peleias e Barbalho (2006) corroboram ressaltando a importância do ensino da contabilidade para que os futuros profissionais possam utilizá-la como: instrumento de auxílio à gestão de negócios, nas etapas de planejamento, execução e controle; ferramenta de controle interno, por possibilitar o registro contábil das operações, 
identificar os responsáveis de tais decisões e obter informações de controle que podem ser estabelecidos nos ciclos de transações empresariais; sistema de informação que abrange os níveis de gestão, para avaliar os resultados dos produtos e serviços, o desempenho dos gestores e áreas de responsabilidade; e instrumento de comunicação da organização com seus usuários da informação contábil.

Partindo dessas informações este estudo tem como problemática: Qual a compreensão que os estudantes dos cursos de Administração e Ciências Econômicas têm em relação ao conteúdo contábil que é ensinado no decorrer desses cursos?

Este trabalho tem o objetivo de verificar a percepção dos discentes dos cursos de Administração e Ciências Econômicas da Fundação Universidade Federal de Rondônia (UNIR) em relação ao ensino de disciplinas de conteúdo contábil.

A pesquisa se justifica pelo fato de que esses discentes estão constantemente envolvidos, em nível de ambiente acadêmico, com a utilização e interpretação de informações contábeis e, como futuros profissionais dessas áreas, é necessário que disponham de entendimento suficiente para apreciar e analisar, adequadamente as informações contábeis.

Além desta introdução, o artigo está estruturado da seguinte forma: referencial teórico, procedimentos metodológicos, resultados e discussões e considerações finais.

\section{REFERENCIAL TEÓRICO}

Nesta seção são abordados os fundamentos teóricos que embasam o presente estudo, a gestão do conhecimento, o ensino e aprendizagem de disciplinas de conteúdo contábil, a evolução do pensamento contábil, a importância do conhecimento contábil nos cursos de Administração e Ciências Econômicas e a contextualização desses cursos.

\subsection{GESTÃO DO CONHECIMENTO}

De acordo com Wiig (1993), afirma que gestão do conhecimento é a construção sistemática, explícita e intencional do conhecimento e sua aplicação para maximizar a eficiência e o retorno sobre ativos de conhecimento da organização. Um entendimento claro sobre essa questão é oferecido por Teixeira Filho (2000, p.22) em sua definição de gestão do conhecimento como "uma coleção de processos que governam a criação, 
disseminação e utilização do conhecimento para atingir plenamente os objetivos da organização". Probst, Raub e Romhardt (2002) identificam que o objetivo integral da gestão do conhecimento é garantir que o conhecimento que a organização possui seja aproveitado da melhor forma em seu benefício, pois o simples reconhecimento e partilha não garantem o seu uso nas atividades do dia a dia da organização devido a vários bloqueios para a utilização do conhecimento externo. O Quadro 1 a seguir apresenta os processos essenciais para aplicação da gestão do conhecimento.

\section{Quadro 1 - Processo da Gestão do Conhecimento}

\begin{tabular}{|l|l|}
\hline \multicolumn{1}{|c|}{ Processo } & \multicolumn{1}{|c|}{ Descrição } \\
\hline $\begin{array}{l}\text { Identificação do } \\
\text { Conhecimento }\end{array}$ & $\begin{array}{l}\text { É preciso identificar o conhecimento, tanto interno como externo, conhecer e } \\
\text { definir habilidades, informações e dados internos e externos, assim } \\
\text { consequentemente se conseguirá uma transparência facilitando para os } \\
\text { funcionários encontrarem o que necessitam. }\end{array}$ \\
\hline $\begin{array}{l}\text { Aquisição do } \\
\text { Conhecimento }\end{array}$ & $\begin{array}{l}\text { As organizações estão constantemente adquirindo conhecimento, tanto } \\
\text { proveniente de meios externos, clientes, fornecedores, concorrentes ou } \\
\text { parceiros, como comprando por meio de recrutamento de profissionais } \\
\text { capacitados ou então por meio de consultorias. }\end{array}$ \\
\hline Desenvolvimento do & $\begin{array}{l}\text { É um complemento a aquisição do conhecimento, é voltado a criação e } \\
\text { desenvolvimento de novas habilidades, novos produtos, novas ideias, } \\
\text { aproveitando o conhecimento que a empresa adquiriu e desenvolvendo } \\
\text { capacidades. }\end{array}$ \\
\hline $\begin{array}{l}\text { Compartilhamento e } \\
\text { distribuição do } \\
\text { conhecimento }\end{array}$ & $\begin{array}{l}\text { É fundamental em qualquer empresa, é a transmissão do conhecimento. O } \\
\text { indivíduo ou grupo que o possui procura uma melhor forma de passar esse } \\
\text { conhecimento para os demais. }\end{array}$ \\
\hline Utilização do conhecimento & $\begin{array}{l}\text { Não basta ter, é preciso utilizar. O conhecimento precisa ser aplicado nas } \\
\text { organizações, mas infelizmente em muitas empresas ainda existem vários } \\
\text { obstáculos impedindo seu uso. }\end{array}$ \\
\hline $\begin{array}{l}\text { Étenção do } \\
\text { Conhecimento } \\
\text { um conhecimento, sendo necessário uma Gestão do Conhecimento, organizando } \\
\text { e com certa frequência atualizá-los para não correr o risco de perdê-los. }\end{array}$ \\
\hline
\end{tabular}

Fonte: Probst, Raub e Romhardt (2002).

Percebe-se que os conceitos de gestão do conhecimento são semelhantes, não há vertentes, princípios ou enfoques diferentes nos enunciados. Todos eles trazem a ideia de que a "gestão do conhecimento" está relacionada com "processos controlados, que têm por objetivo permitir sua disseminação entre um dado grupo de receptores" (FLEURY; OLIVEIRA JR, 2001, p.19).

\subsection{ENSINO E APRENDIZAGEM DE DISCIPLINAS DE CONTEUDO CONTÁBIL}


Em relação ao ensino da Contabilidade, Zgaib (2007) afirma que, o professor tem uma tarefa de trazer o conteúdo para o mundo do estudante da maneira mais simples e real possível, o que não é muito fácil, já que se trata de um assunto "abstrato e cinza".

O estudo da contabilidade em cursos de administração e ciências econômicas para Iudicíbus e Marion (2008) é preliminarmente um problema de foco encontrado nas disciplinas destinadas a esses cursos, sendo estudados lançamentos contábeis à exaustão, confecção de livros razão e diário, fechamento de balancetes, e outros, que demonstram procedimentos técnicos comumente atribuído aos contadores, sendo que é necessário frisar o conteúdo que realmente seja o foco da contabilidade: o fornecimento de informações com base na interpretação das demonstrações contábeis, proporcionando ações gerenciais e econômicas.

Esse tecnicismo da contabilidade impacta na motivação dos discentes. Sá (1997) e Molina (2001) corroboram em parte com as ideias de Iudicíbus e Marion (2008), afirmando que, para motivar os discentes de outros cursos, como administração e ciências econômicas, o ensino da contabilidade deve partir dos relatórios contábeis, para, posteriormente, se chegar à origem daquela informação, ou seja, a escrituração. Isso porque a escrituração é vista como uma prática básica, o que pode conduzir o discente a pensar que a profissão se resume a isso. A ideia é executar o processo inverso, levando o discente a compreender que as demonstrações contábeis são fonte de informação e não como uma mera consequência da escrituração contábil.

\subsection{EVOLUÇÃO DO PENSAMENTO CONTÁBIL}

Desde o início da civilização a contabilidade já existia, e com a evolução da sociedade, vem acompanhando as mudanças no sentido cultural, econômico, político, social e científico. Seu desenvolvimento foi contínuo à medida em que o homem buscava novas fontes para aprimorar seus conhecimentos.

Segundo afirma Silva e Pires (2009) a evolução do pensamento contábil tem acompanhado o desenvolvimento das sociedades desde os primórdios, com base nas teorias dos pensadores da antiga Escola Italiana e da mais recente Escola Norte Americana. Neste sentido o estudo do pensamento contábil contribui para que se conheça as principais fundamentações práticas e teóricas que contribuíram para o desenvolvimento da contabilidade ao longo da história. 
De acordo com Schmidt (1996) que o pensamento contábil reflete a consciência dos contabilistas, suas opiniões ideais e reflexões de determina época em relação a um conjunto de fenômenos históricos vividos pela contabilidade. Neste contexto a contabilidade vem sofrendo modificações e aperfeiçoamentos, assim como a sociedade ao longo do tempo, ou seja, as mudanças acompanham a evolução da sociedade para atender a suas demandas. Neste sentido estudar o pensamento contábil passado é fundamental para entender o presente e fazer um prolongamento sobre o futuro (SCHMIDT,1996).

Segundo Sá (1997) a contabilidade nasceu com a civilização e jamais deixará de existir em decorrência dela; talvez, por isso, quase sempre seus progressos coincidiram com aqueles que caracterizam os da evolução do homem. Schmidt (2000) afirma que a contabilidade surgiu antes do homem desenvolver a civilidade. Para o autor assim como o homem progrediu, a contabilidade também acompanhou esse progresso, necessário ao desenvolvimento da humanidade. Isso corrobora que, como em outras áreas do conhecimento ligados as Ciências Sociais, a evolução do pensamento contábil é produto do meio social de seus usuários, em termos de espaço e de tempo. Lima (2006) defende a evolução contabilidade em quatro etapas conforme exemplificado no Quadro 2 a seguir.

Quadro 2 - Evolução da contabilidade

\begin{tabular}{|l|l|}
\hline \multicolumn{1}{|c|}{ Período } & \multicolumn{1}{c|}{ Características } \\
\hline $\begin{array}{l}\text { Contabilidade do } \\
\text { mundo antigo }\end{array}$ & $\begin{array}{l}\text { Período que se inicia com a civilização do homem e vai até 1202 da Era Cristã, } \\
\text { quando apareceu o Líber Abaci, da autoria Leonardo Fibonaci, o Pisano. }\end{array}$ \\
\hline $\begin{array}{l}\text { Contabilidade do } \\
\text { mundo medieval }\end{array}$ & $\begin{array}{l}\text { Período que vai de 1202 da Era Cristã até 1494, quando apareceu o Tratactus de } \\
\text { Computis et Seriptures (Contabilidade por Partidas Dobradas) de Frei Luca Pacioli, } \\
\text { publicado em 1494; enfatizando que à teoria contábil do débito e do crédito } \\
\text { corresponde à teoria dos números positivos e negativos, obra que contribui para } \\
\text { inserir a contabilidade entre os ramos do conhecimento humano. }\end{array}$ \\
\hline $\begin{array}{l}\text { Contabilidade do } \\
\text { mundo moderno }\end{array}$ & $\begin{array}{l}\text { Período que vai de 1494 até 1840, com o aparecimento da Obra "La Contabilità } \\
\text { Applicatta Alle Amninistrazioni Private e Pubbliche", da autora de Francesco Villa, } \\
\text { premiada pelo governo da Áustria. Obra marcante na história da Contabilidade. }\end{array}$ \\
\hline $\begin{array}{l}\text { Contabilidade do } \\
\text { mundo científico }\end{array}$ & Período que se inicia em 1840 e continua até os dias de hoje. \\
\hline
\end{tabular}

Fonte: Lima 2006, p. 1

Com o intuito de uniformização das normas contábeis, a fim de tornar fácil a sua linguagem para diversos países em 28 de dezembro de 2007 foi sancionada a Lei 11.638 que modificou a Lei das Sociedades por Ações 6.404/76. A razão para essa modificação 
foi o processo de convergência dos padrões contábeis locais para os internacionais, alinhando o Brasil ao processo de internacionalização da contabilidade

De acordo com (2010), as mudanças mais significativas que decorrem do processo de internacionalização dos padrões contábeis são as seguintes: primazia da essência sobre a forma, normas contábeis orientadas por princípios e necessidade do exercício do julgamento por parte dos profissionais de contabilidade. Neste contexto se observa como a contabilidade evoluiu para acompanhar as transformações ocorridas ao longo da história.

Não há como afirmar de forma precisa como a contabilidade surgiu, porém, seu desenvolvimento foi acompanhando as transformações sociais ocorridas ao longo da história. As escolas de pensamento contábil contribuíram com essas transformações por meio de suas importantes pesquisas. Neste contexto, conforme afirma Schmidt (1996) a contabilidade sempre buscou atender as necessidades de seus usuários, independente de quais foram essas necessidades.

\subsection{IMPORTÂNCIA DO CONHECIMENTO CONTÁBIL NOS CURSOS DE ADMINISTRAÇÃO E CIÊNCIAS ECONÔMICAS}

Segundo Marion (2008) é preciso que o profissional de administração conheça e saiba interpretar os relatórios contábeis, tais como o balanço patrimonial, a demonstração de lucros e prejuízos acumulados, a demonstração do resultado do exercício, a demonstração dos fluxos de caixa e a demonstração do valor adicionado. É necessário que ele tenha habilidades para fazer análises contábeis, reconhecer os custos e as respectivas formas de custeio, além de ter ciência do processo contábil.

A contabilidade como um instrumento de análise, gerência e decisão, utiliza-se de suas demonstrações para o gerenciamento e planejamento estratégico, informa aos usuários a situação econômica e financeira da empresa, facilitando a tomada de decisões. Esses subsídios são imprescindíveis para que o administrador e o economista atuem com competência na execução da atividade operacional. Na visão do autor a contabilidade é responsável por coletar os dados econômicos, mensurá-los monetariamente, registrá-los e sumarizá-los em relatórios ou comunicados que sejam de fácil entendimento para os gestores e dirigentes que planejam e controlam as organizações. 
De acordo com Hendriksen e Van Breda (1999, p.104-105), “o objetivo da contabilidade é fornecer um conjunto de relatórios financeiros para usuários determinados com relação à riqueza ou relações econômicas da empresa". Nesse sentido, as disciplinas de conteúdo contábil estão ligadas à geração de informação para o cumprimento dos objetivos das empresas, além de ser essencial nos controles, planejamento e avaliação de gastos, como também, gerar subsídios e sustentabilidade na formação desses acadêmicos. (CRISPIM e MIRANDA, 2013).

Nesse mesmo sentido afirma Iudícibus et. al. (2010), que a contabilidade, tem o propósito de registrar e interpretar os fenômenos que afetam o patrimônio de pessoas físicas ou jurídicas, tem também como usuários de suas informações, os economistas. Aqueles que trabalham na área governamental utilizam as informações oriundas da Contabilidade tributar e arrecadar impostos. Para aqueles que cuidam de análises globais ou setoriais da economia, os dados contábeis tratados estatisticamente, irão auxiliar no fornecimento de instrumentos adequados para análises econômicas.

Autores como Marion (2007) e Iudícibus et al. (2010) destacam a importância da contabilidade para a administração em seu processo decisório, dada sua utilidade em fornecer informações essencialmente necessárias para o processo de tomada de decisão.

Diante do exposto fica evidenciado que tanto administradores como economistas terão que recorrer as informações e ferramentas disponibilizadas pela contabilidade para cumprir os objetivos de qualquer organização

\subsection{CONTEXTUALIZAÇÃO DOS CURSOS DE ADMINISTRAÇÃO E CIÊNCIAS ECONÔMICAS NA UNIR}

$\mathrm{Na}$ área das Ciências Sociais Aplicadas na UNIR, o Núcleo de Ciências Sociais Aplicadas (NUCSA) é responsável pela formação dos profissionais nesta área de conhecimento. O NUCSA ${ }^{6}$ congrega os Departamentos Acadêmicos de Administração, Biblioteconomia, Ciências Contábeis, Ciências Econômicas e Ciências Jurídicas e os Programas de Mestrado Acadêmico em Administração e Mestrado Profissional em Administração Pública.

6 Fundação Universidade Federal de Rondônia (UNIR). Núcleo de Ciências Sociais Aplicadas. Disponível em: < http://www.nucsa.unir.br>. Acesso em 26 de ab. 2019. 
O NUCSA, teve sua origem em 1980 a partir da criação dos três primeiros cursos de graduação que deram origem a UNIR, que foram os cursos de Administração, Ciências Contábeis e Ciências Econômicas, com funcionamento no período noturno. O departamento de Ciências Contábeis presta suporte em relação ao ensino de disciplinas contábeis para os cursos de Administração e Ciências Econômicas, cedendo professores para ministrarem aulas nos referidos cursos.

O curso de Administração ${ }^{7}$ do Campus de Porto Velho forma profissional com visão crítica, com alto grau de conhecimento teórico científico e embasamento prático, com ênfase nas áreas específicas e carências da região, para poder desempenhar com competência as atividades da Ciência da Administração, quer na área pública, quer na área privada.

O Campus universitário em Porto Velho é o mais antigo, criado em 1980, a partir desta data vem colocando profissionais de administração no mercado de trabalho, tendo o maior nível de aprovação nos concursos públicos e seleções de cargos de gestão em empresas privadas e ainda, destacando-se com o maior número de professores nas faculdades privadas de Porto Velho (UNIR, 2019).

O curso de Administração no Campus de Porto velho possui as seguintes características: implantado em 1980, habilitação em Bacharel em Administração, duração de 4 anos, formação profissional Administração. A última atualização do projeto pedagógico do curso de Administração é de 2006.

A formação do administrador é regulamentada pela Lei n. 4769/65. As Diretrizes Curriculares Nacionais do Curso de Graduação em Administração trazem em seus artigos $3^{\circ}$ e $5^{\circ}$ o perfil desejado dessa profissão:

Art. $3^{\circ}$. O curso de graduação em Administração deve ensejar, como perfil desejado do formando, capacitação e aptidão para compreender as questões científicas, técnicas, sociais e econômicas da produção e de seu gerenciamento, observados níveis graduais do processo de tomada de decisão, bem como para desenvolver gerenciamento qualitativo e adequado, revelando a assimilação de novas informações e apresentando flexibilidade intelectual e adaptabilidade contextualizada no trato de situações diversas, presentes ou emergentes, nos vários segmentos do campo de atuação do administrador.

7 Fundação Universidade Federal de Rondônia (UNIR). Departamento de administração. Disponível em: <http://www.departamentoadm.unir.br>. Acesso em 28 de mai. 2019. 
[...] Art. $5^{\circ}$. Os cursos de graduação em Administração deverão contemplar, em seus projetos pedagógicos e em sua organização curricular, conteúdos que revelem inter-relações com a realidade nacional e internacional, segundo uma perspectiva histórica e contextualizada de sua aplicabilidade no âmbito das organizações e do meio através da utilização de tecnologias inovadoras e que atendam aos seguintes campos interligados de formação:

I - Conteúdos de formação básica: relacionados com estudos antropológicos, sociológicos, filosóficos, psicológicos, éticoprofissionais, políticos, comportamentais, econômicos e contábeis, bem como os relacionados com as tecnologias da comunicação e da informação e das ciências jurídicas; [...] (BRASIL, 014e).

Percebe-se que, a necessidade de formação básica dos conhecimentos contábeis, que auxiliará na tomada de decisão, sobretudo, relacionada à saúde financeira da empresa.

Os discentes do curso de Administração da UNIR em sua matriz curricular possuem as seguintes disciplinas contábeis com suas respectivas ementas:

- Contabilidade Geral I ( $2^{\circ}$ Período): Campo de atuação o objeto da contabilidade. Conceitos contábeis básicos. Registros e procedimentos contábeis básicos, o patrimônio, estrutura e variação. Registros contábeis. Despesas e receitas. Balanço patrimonial. Plano de contas. Sistemas contábeis. Análise de questões contábeis. Relatórios contábeis. Aplicação dos conhecimentos da ciência e da técnica contábil voltado a estruturação de balanços e do conjunto dos demonstrativos contábeis, variações do patrimônio líquido, Uso da Informação contábil pela administração. Indicadores econômicos e financeiros.

- Contabilidade Geral II (3 ${ }^{\circ}$ Período): Uso da informação contábil pela administração. Estrutura das demonstrações financeiras. Instrumental básico de análise. Análise e interpretação econômico-financeira. Análise do patrimônio, estrutura e variação. Despesas e receitas. Plano de contas. Instrumental básico de análise. Auditoria. Indicadores econômicos e financeiros.

- Contabilidade de Custos (4 ${ }^{\circ}$ Período): Introdução ao Sistema de Custos; Rateio em Custos; Modelos de Custeio; Regime ABC; Métodos de Custeio Padrão, UEPS, PEPS e Centro de Custos.

- Análise de Custos e Formação de Preços (5ºríodo): Custos Fixos e Variáveis. Relação custo volume-lucro e ponto de equilíbrio contábil, econômico e financeiro. Alavancagem operacional. Custeio direto ou variáveis. Margem de 
contribuição e limitações na capacidade produtiva. Decisões especiais: produzir ou comprar, alterações de tecnologia. Critérios de avaliação dos estoques e sistemas de custos. Custo departamental. Análise das variações entre padrão e real.

O curso de Ciências Econômicas ${ }^{8}$ forma profissional apto a atender as variadas demandas da sociedade em toda a sua complexidade e heterogeneidade. O curso do Ciências Econômicas da Universidade Federal de Rondônia consolida-se por meio da formação de Bacharéis em Ciências Econômicas, promovendo o ensino, a pesquisa e a extensão. Tem como objetivo ampliar os horizontes intelectuais (constituindo uma base cultural ampla, que possibilite o entendimento de questões econômicas no seu contexto histórico-cultural) de modo a propiciar as competências e habilidades da profissão (UNIR, 2019).

Criado em 1980 juntamente com os cursos de Administração, Ciências Contábeis, com funcionamento no período noturno o curso de Ciências Econômicas é do tipo Bacharelado e dura em média quatro anos. A última atualização do projeto pedagógico do curso de Ciências Econômicas ocorreu no ano de 2014.

A formação de economista é regulamentada pela Lei n. 1.411 de 13 de agosto de 1951. De acordo com as Diretrizes Curriculares Nacionais do Curso de Graduação em Ciências Econômicas, artigos $3^{\circ}$ e $5^{\circ}$, o perfil desejado de um Economista, e o conteúdo necessário do projeto pedagógico, o qual deve incluir a formação básica dos conhecimentos em Contabilidade:

Art. $3^{\circ}$. O curso de graduação em Ciências Econômicas deve ensejar, como perfil desejado do formando, capacitação e aptidão para compreender as questões científicas, técnicas, sociais e políticas relacionadas com a economia, revelando assimilação e domínio de novas informações, flexibilidade intelectual e adaptabilidade, bem como sólida consciência social indispensável ao enfrentamento de situações e transformações políticoeconômicas e sociais, contextualizadas, na sociedade brasileira e no conjunto das funções econômicas mundiais.

$[\ldots]$

Art. $5^{\circ}$. Os cursos de graduação em Ciências Econômicas deverão contemplar, em seus projetos pedagógicos e em sua organização curricular, conteúdos que revelem inter-relações com a realidade

8 Fundação Universidade Federal de Rondônia (UNIR). Departamento de Ciências

Econômicas. Disponível em:<http://www.decon.unir.br >. Acesso em 26 de mai.2019. 
nacional e internacional, segundo uma perspectiva histórica e contextualizada dos diferentes fenômenos relacionados com a economia, utilizando de tecnologias inovadoras, e que atendam aos seguintes campos interligados de formação:

I - Conteúdos de formação geral, que têm por objetivo introduzir o aluno ao conhecimento da ciência econômica e de outras ciências sociais, abrangendo também aspectos da filosofia e da ética (geral e profissional), da sociologia, da ciência política e dos estudos básicos e propedêuticos da administração, do direito, da contabilidade, da matemática e da estatística econômica; [...] (BRASIL, 2014). O profissional de Economia que souber interpretar as informações contidas em relatórios fornecidos pela Contabilidade, tais como Balanço Patrimonial, Demonstração do Fluxo de Caixa e Demonstração do Resultado, poderá traçar tendências econômicas assertivas que contribuirão inclusive para a perenidade e a sustentabilidade da empresa. (BRASIL, 2014)

Os discentes do curso de Economia da UNIR em sua matriz curricular possuem as seguintes disciplinas contábeis com suas respectivas ementas:

- Contabilidade Social (2 ${ }^{\circ}$ Período): Conceituação e análise dos agregados macroeconômicos: óticas de mensuração dos principais agregados macroeconômicos. Sistemas de contas nacionais. Esquemas de insumo-produto: matrizes de insumo-produto como instrumento de análise e programação econômica. Contabilidade a preços constantes: índices de preços e quantidades. Noções gerais sobre balanço de pagamentos.

- Análise das Demonstrações Financeiras (2ºríodo): Balanço Patrimonial; Demonstrações do Resultado do Exercício; Fluxo de Caixa. Fontes de dados para Análise das Demonstrações; Usuários das Demonstrações Contábeis; Análise das Demonstrações Financeiras: Análise Horizontal; Análise Vertical; Análise por meio dos Índices Econômicos e Financeiros: Estrutura de Capital; Liquidez e Solvência; Atividade ou Rotatividade; Rentabilidade; Ciclo Operacional e Ciclo Financeiro; Índices de Mercado.

\section{MÉTODOS E TÉCNICAS DE PESQUISA}

Esta pesquisa foi realizada na Fundação Universidade Federal de Rondônia, instituída pela Lei n. ${ }^{\circ} 7011$, de 08 de julho de 1982, que a integra ao Sistema Federal de Ensino (BRASIL, 1982). É composta por estrutura multicampi, com sede na cidade de Porto Velho, sendo a única universidade pública do Estado de Rondônia (UNIR, 2014). 
O foco são os discentes dos cursos de graduação de Administração e Ciências Econômicas.

Quanto à forma de abordagem do problema esta pesquisa classifica-se como quantitativa e qualitativa. Quantitativa por efetuar-se a mensuração dos dados coletados, transformando-os em indicadores para futuras análises, que de acordo com Raupp e Beirem (2009), uma vez que será utilizada a estatística e os dados quantitativos tanto na coleta quanto na análise das informações.

Também é uma pesquisa qualitativa em função da análise e interpretação das informações obtidos nas questões abertas do instrumento de pesquisa que associados à pesquisa quantitativa e com os dados obtidos na pesquisa teórica, que segundo Raupp e Beirem (2006, p. 92) "na pesquisa qualitativa concebem-se análises mais profundas em relação ao fenômeno que está sendo estudado".

De acordo com o objetivo, essa pesquisa caracteriza-se como descritiva. A pesquisa descritiva tem como principal objetivo descrever características de determinada população, ou fenômeno, ou o estabelecimento de relação entre as variáveis; comumente utiliza técnicas padronizadas para a coleta de dados (GIL, 2008).

No que se refere aos procedimentos técnicos utilizados, o presente estudo classifica-se como levantamento, cuja base de dados foi extraída por meio de um questionário com perguntas abertas e fechadas, adaptado de Bianchi et al. (2013), sendo este dividido em três partes. Na primeira parte, foi construído o perfil dos respondentes e na segunda parte, o questionário é composto por questões fechadas, sob a forma de frases afirmativas e os respondentes devem indicar sua opinião favorável ou desfavorável quanto à afirmação feita, sendo utilizada a escala Likert com cinco pontos, considerando o nível de satisfação dos discentes, sendo dividido em Discordo totalmente (CT), Discordo Parcialmente (DP), Indiferente (I), Concordo Parcialmente (CP) e Concordo Totalmente (CT); na terceira parte há duas questões subjetivas que serão apreciadas utilizando análise do conteúdo, selecionando as respostas que foram dadas em um sentido mais próximo umas das outras.

Para Bardin (1977, p. 42), a análise de conteúdo é um conjunto de "técnicas de análise das comunicações visando obter, por procedimentos, sistemáticos e objetivos de descrição do conteúdo das mensagens, indicadores [...] que permitam a inferência de conhecimentos relativos às condições de produção/recepção [...] destas mensagens". O questionário com as afirmativas foi apresentado aos respondentes, os dados obtidos foram 
apreciados e organizados utilizando-se do Microsoft Office Excel e posteriormente foram avaliados com as ferramentas matemáticas e gráficas do software.

O universo de pesquisa escolhido para elaboração deste trabalho foram os discentes dos cursos de Administração e Ciências Econômicas da Universidade Federal de Rondônia -UNIR, sendo que dentro deste contexto, serão pesquisados os discentes do sexto e sétimo período do curso de Administração, e os discentes do quinto e sexto período do curso de Ciências Econômicas, pois os mesmos já estudaram todas as disciplinas contábeis ofertadas nos seus respectivos cursos nos períodos anteriores.

\section{RESULTADOS E DISCUSSÕES}

O questionário apresentado aos respondentes contou com o somatório de sessenta e três (63) respondentes na universidade, correspondente à soma dos discentes do quinto e sexto período do curso de Ciências Econômicas 34 (trinta e quatro), juntamente com os discentes do sexto e sétimo período do curso de Administração 29 (vinte e nove).

Em relação ao total de respondentes (63), 63\% em sua maior parte estão na faixa etária de 18 à 25 anos, 56\% do sexo masculino, sendo $48 \%$ estão cursando o quinto período, $32 \%$ o sexto período e $21 \%$ o sétimo período dos seus respectivos cursos. A aplicação do questionário resultou no Quadro 3 a seguir; correspondem 15 afirmativas e as opções assinaladas pelos respondentes na Escala de Likert.

Quadro 3 - Tabulação dos dados da consulta ao grupo foco da pesquisa.

\begin{tabular}{|c|c|c|c|c|c|c|}
\hline AFIRMATIVAS & DT & DP & I & $\mathbf{C P}$ & CT & TOTAL \\
\hline 1. A disciplinas contábeis foram de fácil entendimento. & $8 \%$ & $19 \%$ & $6 \%$ & $51 \%$ & $16 \%$ & $100 \%$ \\
\hline $\begin{array}{l}\text { 2. A organização dada aos conteúdos da disciplina facilita a } \\
\text { minha compreensão. }\end{array}$ & $5 \%$ & $11 \%$ & $19 \%$ & $38 \%$ & $27 \%$ & $100 \%$ \\
\hline $\begin{array}{l}\text { 3. Os enfoques das disciplinas foram coerentes com os } \\
\text { objetivos do meu curso. }\end{array}$ & $2 \%$ & $10 \%$ & $8 \%$ & $46 \%$ & $35 \%$ & $100 \%$ \\
\hline $\begin{array}{l}\text { 4. Os conteúdos abordados nas disciplinas contábeis foram } \\
\text { importantes para o meu curso. }\end{array}$ & $3 \%$ & $3 \%$ & $6 \%$ & $30 \%$ & $57 \%$ & $100 \%$ \\
\hline $\begin{array}{l}\text { 5. Os objetivos de aprendizagem da disciplina foram } \\
\text { alcançados. }\end{array}$ & $2 \%$ & $14 \%$ & $13 \%$ & $35 \%$ & $37 \%$ & $100 \%$ \\
\hline $\begin{array}{l}\text { 6. As disciplinas agregaram conhecimento para posterior } \\
\text { aplicação. }\end{array}$ & $3 \%$ & $10 \%$ & $5 \%$ & $35 \%$ & $48 \%$ & $100 \%$ \\
\hline $\begin{array}{l}\text { 7. As disciplinas presentes na grade curricular foram } \\
\text { adequadas para o aprendizado. }\end{array}$ & $3 \%$ & $11 \%$ & $6 \%$ & $46 \%$ & $33 \%$ & $100 \%$ \\
\hline 8. O aluno se empenhou para o aprendizado das disciplinas. & $5 \%$ & $8 \%$ & $16 \%$ & $43 \%$ & $29 \%$ & $100 \%$ \\
\hline $\begin{array}{l}\text { 9. Procuro estabelecer relação entre o conteúdo abordado na } \\
\text { disciplina e outros conteúdos ou fatos já conhecidos. }\end{array}$ & $2 \%$ & $11 \%$ & $13 \%$ & $43 \%$ & $32 \%$ & $100 \%$ \\
\hline
\end{tabular}




\begin{tabular}{|l|c|c|c|c|c|c|}
\hline $\begin{array}{l}\text { 10. Os conhecimentos adquiridos proporcionaram aos } \\
\text { discentes a capacidade de elaborar demonstrações contábeis } \\
\text { básicas. }\end{array}$ & $5 \%$ & $14 \%$ & $17 \%$ & $48 \%$ & $16 \%$ & $100 \%$ \\
\hline \begin{tabular}{l} 
11. Me sinto apto a interpretar informações contábeis. \\
\hline $\begin{array}{l}\text { 12. Os professores tinham capacidade de síntese e clareza nas } \\
\text { exposições. }\end{array}$
\end{tabular} & $6 \%$ & $29 \%$ & $22 \%$ & $32 \%$ & $11 \%$ & $100 \%$ \\
\hline $\begin{array}{l}\text { 13. O professor trabalhou os conteúdos da disciplina, } \\
\text { destacando aspectos importantes da matéria. }\end{array}$ & $6 \%$ & $16 \%$ & $16 \%$ & $37 \%$ & $25 \%$ & $100 \%$ \\
\hline $\begin{array}{l}\text { 14. O professor atendeu as necessidades de aprendizagem dos } \\
\text { discentes. }\end{array}$ & $8 \%$ & $17 \%$ & $21 \%$ & $25 \%$ & $29 \%$ & $100 \%$ \\
\hline $\begin{array}{l}\text { 15. O professor proporcionou motivação necessária para o } \\
\text { aprendizado dos discentes. }\end{array}$ & $13 \%$ & $22 \%$ & $14 \%$ & $27 \%$ & $24 \%$ & $100 \%$ \\
\hline
\end{tabular}

Fonte: Adaptado Bianchi (2013)

Para uma maior compreensão dos dados tabulados, o presente trabalho dividiu a análise do Quadro 3 em avaliação das disciplinas, autoavaliação dos discentes e avaliação dos professores.

\subsection{AVALIAÇÃO DAS DISCIPLINAS}

O Gráfico 1 refere-se a avaliação das disciplinas e contempla sete afirmativas, tratando a facilidade do entendimento, a organização dos conteúdos, a coerência do enfoque dos conteúdos abordados, a importância da disciplina para a formação do discente, os objetivos de aprendizagem, agregação de conhecimento proporcionada pelas disciplinas e as disciplinas em relação à grade curricular. 


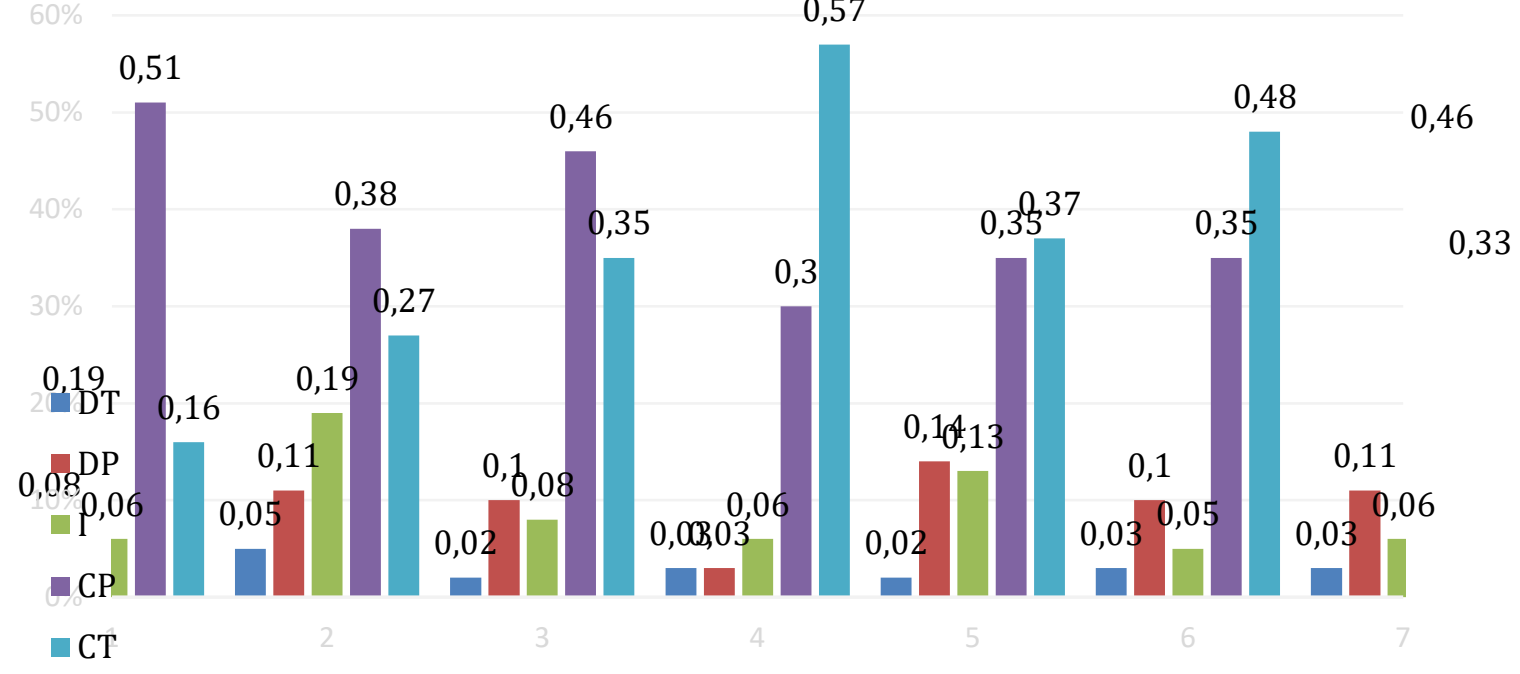

Gráfico 1- Avaliação das disciplinas

Fonte: dados da pesquisa (2019)

Com base nas informações do Gráfico 1, pode-se afirmar que as respostas com valores de (CP) e (CT) apresentam-se em maior quantidade para todas as afirmativas, o que indica a uma boa avaliação por parte dos discentes. A somas dos discentes que concordam que as disciplinas foram de fácil entendimento é de $67 \%$, outro ponto positivo é a organização dada aos conteúdos que contribuem para o aprendizado, que somam a concordância de $65 \%$. Em relação ao conteúdo, a avaliação demonstra que os discentes, em sua grande parte, admitem que há uma boa adequação das disciplinas aos objetivos do curso de graduação somando um total de concordância de $81 \%$ o que corrobora com (ETTER; BURMEISTER; ELDER, 2000), que afirmam que um dos objetivos do ensino da contabilidade para os cursos de Administração e Ciências Econômicas é preparar os discentes, durante a graduação, para outras disciplinas do curso.

Ainda em relação ao Gráfico 1, os discentes também pontuaram de forma positiva a importância dos conteúdos ministrados para sua formação profissional e futura atuação, somando a concordância de $87 \%$, o que corrobora com Hernandes, Peleias e Barbalho (2006) que ressaltam a importância do ensino da contabilidade para que os futuros profissionais possam utilizá-la como 
instrumento de auxílio à gestão de negócios, nas etapas de planejamento, execução e controle.

Em relação aos objetivos da aprendizagem serem alcançados um total de $72 \%$ concordam que esse aspecto foi atingido. Os discentes também concordam em sua grande maioria em um somatório de $83 \%$ que as disciplinas agregaram conhecimento para posterior aplicação. No que se refere as disciplinas de conteúdo contábil em relação à grade curricular ofertada $79 \%$ concordam que esse aspecto contribuiu para seu aprendizado.

\subsection{AUTOAVALIAÇÃO DOS DISCENTES}

O Gráfico 2 a seguir trata sobre a autoavaliação dos discentes e contempla quatro afirmativas, tratando o empenho para aprendizado, a relação que o aluno utiliza o conhecimento contábil para outras matérias, a capacidade de elaborar demonstrações contábeis básicas e a aptidão de interpretar informações contábeis.

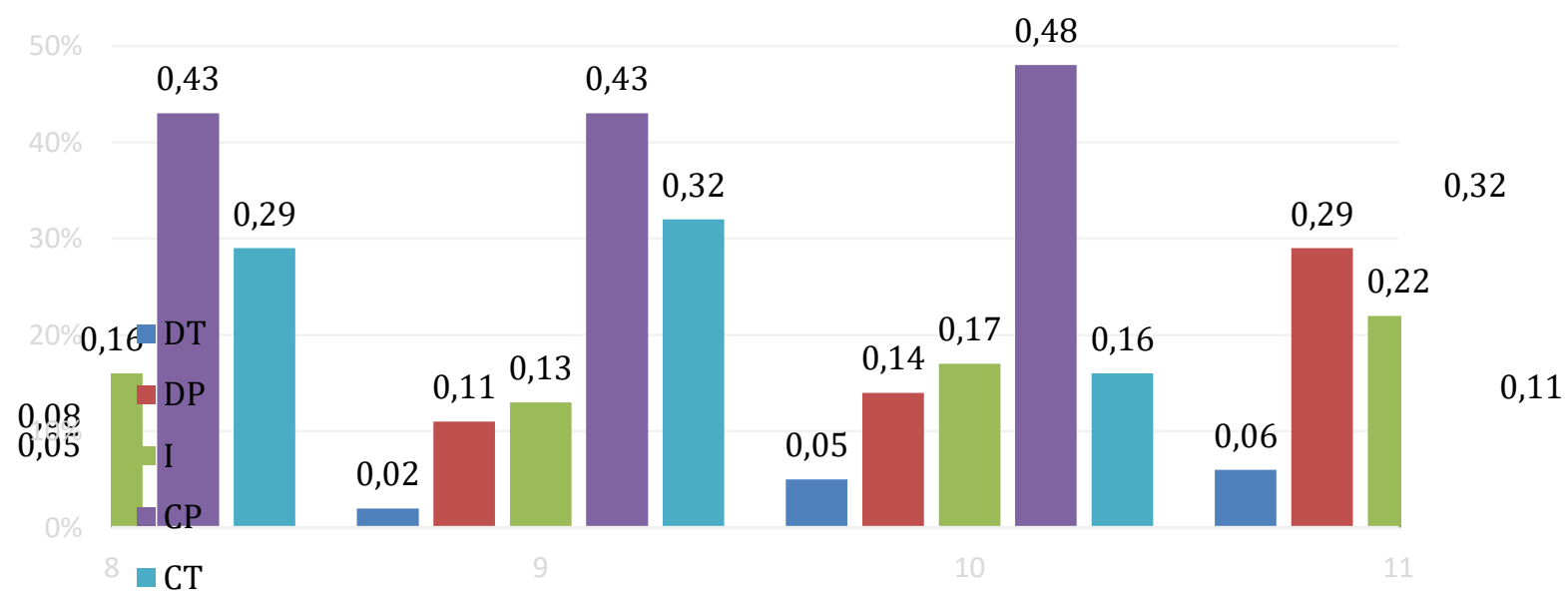

Gráfico 2- Autoavaliação dos discentes

Fonte: dados da pesquisa (2019)

Em relação ao empenho ou esforço da parte dos discentes para o efetivo aprendizado das matérias soma-se um total de $72 \%$ que concordam positivamente com esse entendimento. Os respondentes também pontuaram positivamente para uso do aprendizado dessas disciplinas contábeis em outras áreas, somando um total de 75\% de 
concordância, o que pode indicar uma boa assimilação desses conteúdos contábeis. No que se refere à capacidade de elaborar demonstrações contábeis básicas $48 \%$ assinalaram que concordam parcialmente e somente $16 \%$ assinalaram que concordam totalmente, o que pode indicar que, apesar de ter um alto grau na soma das concordâncias, provavelmente há alguma lacuna ou dúvidas no conhecimento adquirido. Em relação à aptidão para interpretar informações contábeis $43 \%$ concordam que possuem essa habilidade, todavia mostra-se uma parcela de $35 \%$ que discordam e $22 \%$ ficam indiferente a essa informação, o que indica a necessidade de melhora desses índices.

\subsection{AVALIAÇÃO DOS PROFESSORES}

O Gráfico 3 trata sobre a avaliação dos professores e contempla quatro afirmativas, tratando a capacidade de síntese e clareza nas exposições, a didática do professor, capacidade de suprir as necessidades de aprendizagem dos discentes e a capacidade de motivação para o aprendizado.

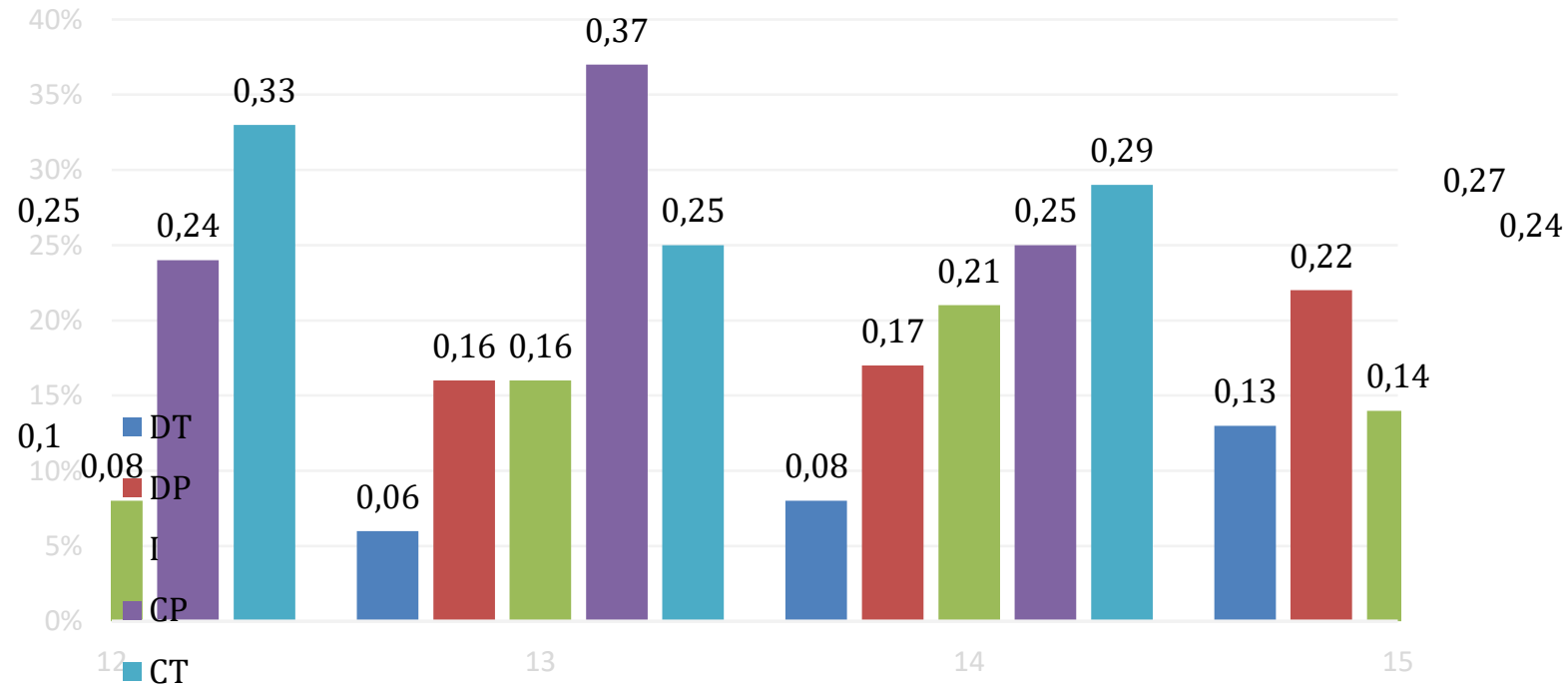

Gráfico 3- Avaliação dos professores

Fonte: dados da pesquisa (2019)

Em relação à capacidade de síntese e clareza nas exposições dos professores 59\% assinalam positivamente concordando com a afirmativa, o que corrobora Zgaib (2007), que afirma que o professor tem uma tarefa de trazer o conteúdo para o mundo do estudante da maneira mais simples e real possível. Quanto à didática dos professores, $62 \%$ dos 
respondentes concordam que o professor trabalhou os conteúdos da disciplina, destacando aspectos importantes da matéria.

Em relação a capacidade de suprir as necessidades de aprendizagem dos discentes, $54 \%$ dos discentes concordam que os professores possuem essa habilidade, todavia há uma necessidade de aperfeiçoamento desses índices, pois a soma dos que marcaram indiferente e discordantes totalizam $46 \%$. No que se refere à capacidade de motivação para o aprendizado, totalizam-se $51 \%$ positivamente para a concordância, corroborando para a ideia de Sá (1997) Molina (2001), que afirma que é necessário que o docente tenha a capacidade de motivação para o ensino de disciplinas contábeis, levando o discente a compreender as demonstrações contábeis com fonte de informação, mas indicam uma necessidade de aprimoramento.

\subsection{QUESTÕES DISCURSIVAS}

As próximas questões do questionário aplicado foram abertas, com o objetivo de entender a contribuição dos discentes e da coordenação dos cursos para o sucesso das disciplinas. A pergunta "1" foi respondida por 25 (vinte e cinco) de um total de 27 (vinte e sete) respondentes do curso de Administração. A afirmativa "2" foi respondida por 26 (vinte e seis) de um total de 27 (vinte e sete) respondentes.

Em relação ao curso de Ciências Econômicas a pergunta "1" foi respondida por 34 (trinta e quatro) discentes de um total de 36 respondentes e a afirmativa " 2 " foi respondida por 34 (trinta e quatro) dos 36 (trinta seis) respondentes.

Quadro 4- Estratificação das respostas dos discentes do curso de Administração

\begin{tabular}{|l|l|}
\hline \multicolumn{1}{|c|}{ Pergunta } & \multicolumn{1}{c|}{ Algumas respostas } \\
\hline $\begin{array}{l}\text { 1.De que forma você contribuiu para } \\
\text { sucesso das disciplinas? }\end{array}$ & $\begin{array}{l}\text { Estudando em sala e procurando assimilar o conteúdo, questionando } \\
\text { quando não compreendia. }\end{array}$ \\
\hline & Com esforço, dedicação e prestando atenção nas aulas. \\
\hline $\begin{array}{l}\text { 2. Qual a contribuição da da } \\
\text { coordenação para o sucesso das } \\
\text { disciplinas? }\end{array}$ & $\begin{array}{l}\text { Colocou bons professores para ministrar as aulas o que possibilitou } \\
\text { melhor forma de absorção do conteúdo. }\end{array}$ \\
\hline & Pouca contribuição, pois não vi empenho da coordenação. \\
\hline & $\begin{array}{l}\text { Ouvindo as reclamações e sugestões dos discentes para que todos saiam } \\
\text { com o entendimento claro das disciplinas aplicadas. }\end{array}$ \\
\hline
\end{tabular}

Fonte: dados da pesquisa (2019) 
Pela análise das respostas, em relação a pergunta "1" pode-se inferir que os discentes do curso de administração deram maior importância na assimilação do conteúdo. A dedicação e esforço no estudo das disciplinas também predominaram nas respostas. Neste sentido corrobora as afirmações de Iudicíbus e Marion (2008) onde afirmam sobre a importância do estudo dos conteúdos contábeis para os cursos de administração e ciências econômicas.

Em relação a pergunta "2" a parte que se destaca é em relação aos professores, sendo afirmado em grande parte das respostas a qualificação dos mesmos, o que vem a confirmar o que destaca Zgaib (2007) onde afirma que, o professor tem uma tarefa de trazer o conteúdo para o mundo do estudante da maneira mais simples e real possível, ou seja, o objetivo é facilitar a compreensão do aluno. Também houve repostas no sentido de acolher as sugestões e reclamações, para a melhora do curso. Na parte negativa está aqueles que afirmaram não ver empenho da coordenação do curso de Ciências Contábeis em relação as disciplinas contábeis.

Quadro 5- Estratificação das respostas dos discentes do curso de Ciências Econômicas

\begin{tabular}{|l|l|}
\hline \multicolumn{1}{|c|}{ Pergunta } & \multicolumn{1}{|c|}{ Algumas respostas } \\
\hline $\begin{array}{l}\text { 1.De que forma você contribuiu para } \\
\text { sucesso das disciplinas? }\end{array}$ & Estudando e tentando extrair o máximo do docente. \\
\hline & $\begin{array}{l}\text { Dedicando tempo e esforço para compreender os conteúdos lecionados } \\
\text { em sala de aula. }\end{array}$ \\
\hline $\begin{array}{l}\text { Qual a contribuição da da } \\
\text { coordenação para o sucesso das } \\
\text { disciplinas? }\end{array}$ & $\begin{array}{l}\text { Fiz minha parte em relação aos trabalhos e provas e consegui } \\
\text { compreender o que foi aplicado. }\end{array}$ \\
\hline & $\begin{array}{l}\text { Concedendo professores apto pra a disciplina. } \\
\text { reclamação ou elogios. }\end{array}$ \\
\hline & $\begin{array}{l}\text { Trazendo professores capacitados que sabem transmitir de forma fácil e } \\
\text { compreensível. }\end{array}$ \\
\hline
\end{tabular}

Fonte: dados da pesquisa (2019)

Quanto ao curso de Ciências Econômicas as respostas da pergunta "1" foram semelhantes aos discentes do curso de Administração, isto é, dando uma maior ênfase a dedicação e esforço no aprendizado das disciplinas contábeis. Neste sentido a dedicação do aluno é fundamental para o aprendizado das disciplinas contábeis.

Na pergunta " 2 " as respostas também se assemelham as dos discentes do curso de Administração, destacando uma vez mais a capacidade dos professores. Outro ponto de 
destaque em relação a coordenação do curso é além de fornecer professores capacitados para ministrar as disciplinas contábeis, foi na questão de anteder as solicitações dos discentes, seja elas em forma de sugestões ou reclamações.

Este trabalho foi baseado nos estudos elaborados por Bianchi et al. (2013), que realizou uma pesquisa intitulada como: A percepção e o perfil do discente não contador sobre o ensino da disciplina de metodologia de custos; sendo que nesta pesquisa foi realizada de forma mais abrangente para verificar não só a percepção em relação à disciplina de contabilidade de custos, mas todas as disciplinas contábeis presentes na grade curricular dos cursos de Administração e Ciências Econômicas da UNIR.

Este estudo corrobora para alguns resultados obtidos no trabalho de Bianchi (2013), no que se refere à percepção, os discentes reconhecem a importância da disciplina de conteúdos contábeis para suas respectivas áreas de formação. Em contraste com o estudo de Bianchi (2013), evidenciou-se que, boa parte dos discentes responderam que se dedicaram adequadamente aos estudos das disciplinas de conteúdos contábeis, de acordo com suas percepções, somando $75 \%$ de concordância desse entendimento.

Também corrobora em relação aos professores, os discentes reconheceram sua capacidade e disponibilidade. No que se refere à facilidade de entendimento dos conteúdos contábeis, há uma divergência de resultados, nesta pesquisa $67 \%$ concordam que os conteúdos contábeis foram de fácil entendimento, enquanto no trabalho de Bianchi (2013) a grande maioria não concordou com esse entendimento.

\section{CONSIDERAÇÕES FINAIS}

Esta pesquisa teve a finalidade de analisar a percepção dos discentes dos Cursos de Administração e Ciências Econômicas da Fundação Universidade Federal de Rondônia (UNIR), tendo como objetivo verificar o nível de compreensão desses discentes em relação ao conteúdo contábil ensinado no decorrer desses cursos.

Os resultados da pesquisa foram obtidos por meio de um questionário aplicado, com perguntas fechadas que se dividiram em análise em avaliação das disciplinas, autoavaliação dos discentes e avaliação dos professores. Também foi aplicado duas perguntas abertas com o objetivo de entender a contribuição dos discentes e da coordenação dos cursos para o sucesso das disciplinas. 
Verifica-se que as percepções dos respondentes em relação a avaliação das disciplinas como sendo de fácil entendimento. Em relação ao conteúdo, a avaliação demonstra que os discentes, em sua grande parte, admitem que há uma boa adequação das disciplinas aos objetivos do curso de graduação. Ponto a destacar também foi a importância dos conteúdos ministrados para sua formação profissional.

Quanto a autoavaliação dos discentes pontos a destacar é em relação ao empenho e esforço da parte dos discentes para o aprendizado das disciplinas. Também cabe ressaltar a importância do aprendizado dessas disciplinas contábeis para o uso em outras áreas. Existe baixa relação associada no que se refere à capacidade de elaborar demonstrações contábeis básicas e à aptidão para interpretar informações contábeis, o que indica a necessidade de melhora desses índices.

Sobre a análise da avaliação dos professores a percepção dos discentes aponta positivamente para a capacidade de síntese e clareza nas exposições dos mesmos. Quanto à didática do professor a pesquisa aponta que o professor trabalhou os conteúdos da disciplina, destacando aspectos importantes. Ponto a ser melhorado é em relação a capacidade de suprir as necessidades de aprendizagem dos discentes, pois os índices apontaram para essa necessidade. No que se refere à capacidade de motivação para o aprendizado, totalizam-se $51 \%$ positivamente para a concordância, deste índice destacando um ponto importante neste sentido.

Em relação a percepção dos discentes sobre as perguntas abertas, quanto a contribuição dos discentes para o sucesso das disciplinas, pontos relevantes nas respostas se refere importância dada na assimilação do conteúdo, e a dedicação e esforço no estudo das mesmas. Sobre a contribuição da coordenação para o sucesso das disciplinas a parte que se destaca é em relação aos professores, sendo afirmado em grande parte das respostas a qualificação dos mesmos.

Em relação à gestão do conhecimento, a instituição de ensino superior é um tipo de organização formada por pessoas, processos e tecnologia, que produz e propaga conhecimento para a sociedade, no entanto, deve considerar também o gerenciamento do conhecimento interno, sendo que nesta pesquisa foi observado como um todo, um bom gerenciamento desse conhecimento averiguado pela grade curricular ofertada, pelo bom desempenho dos professores em aplicar seus conhecimentos adquiridos e também na própria assimilação dos conteúdos contábeis de acordo com a percepção dos discentes. 
Espera-se que esta pesquisa contribua como referência para o desenvolvimento de novas pesquisas quanto a importância do ensino das disciplinas de conteúdos contábeis nos cursos de Administração e Ciências Econômicas. Admite-se por outro lado a limitação dos resultados, uma vez que a amostra se limitou aos cursos de Administração e Ciências Econômicas da Fundação Universidade Federal de Rondônia (UNIR), sugerindo-se que futuras pesquisas possam ser aplicadas abrangendo as Instituições de Ensino Superior (IES) que possuem os cursos de Administração e Ciências Econômicas.

\section{REFERÊNCIAS}

BARDIN, L. Análise de conteúdo. Lisboa: Edições 70, 1977.

BIANCHI, Márcia et al. A percepção e o perfil do discente não contador sobre o ensino da disciplina de metodologia de custos. Revista Ambiente Contábil, v. 5, n. 2, p. 268-289, 2013.

BRASIL. Lei $\mathbf{n}^{\circ}$ 4.769, de 9 de setembro de 1965. Dispõe sobre o exercício da profissão de Técnico de Administração, e dá outras providências. Diário Oficial da União - Seção 1 - 13/9/1965, Página 9337 (Publicação Original).

BRASIL. Lei no 1.411, de 13 de agosto de 1951. Dispõe sobre a profissão do economista. Disponível em:< http://www.planalto.gov.br/ccivil_03/LEIS/1950-1969/L1411.htm>. Acesso em: 20 julho. 2019.

BRASIL. Ministério da Educação (MEC) - Conselho Nacional de Educação (CNE). Resolução CNE/CES n. ${ }^{\circ}$, de 13 de Julho de 2005. Disponível em: <http://portal.mec.gov.br/cne/arquivos/pdf/rces004_05.pdf>. Acesso em: 20 julho. 2019.

BRASIL. Ministério da Educação (MEC) - Conselho Nacional de Educação (CNE). Resolução CNE/CES $\mathbf{n}^{\mathbf{0}}$ 4, de 13 de julho de 2007. Disponível em: <http://portal.mec.gov.br/cne/arquivos/pdf/2007/rces004_07.pdf>. Acesso em: 20 julho. 2019.

BRASIL. Lei n. ${ }^{0}$ 7011, de 08 de julho de 1982. Autoriza o Poder Executivo a instituir a Fundação Universidade Federal de Rondônia. Disponível em: http://www.planalto.gov.br/ccivil 03/leis/1980-1988/L7011.htm. Acesso em: 23 abril. 2019.

BRASIL. Lei $\mathrm{n}^{\circ} \mathbf{. 1 1 . 6 3 8}$, de 28 de dezembro de 2007. Altera e revoga dispositivos da Lei no 6.404, de 15 de dezembro de 1976, e da Lei no 6.385, de 7 de dezembro de 1976, e estende às sociedades de grande porte disposições relativas à elaboração e divulgação de demonstrações financeiras.

CRISPIM, Gilberto; MIRANDA, Luis Carlos. O ensino da contabilidade no curso de administração de empresa: a percepção do corpo discente das disciplinas de contabilidade na sua formação acadêmica. ASAA-Advances in Scientific and Applied Accounting, v. 5, n. 1, p. 131-155, 2013. 
ETTER, E. R.; BURMEISTER, S. L.; ELDER, R. J. Improving student performance and retention via supplemental instruction. Journal of Accounting Education. Ed. 18, accepted 1, Nov. p. 355-368, 2000.

Fundação Universidade Federal de Rondônia (UNIR). Núcleo de Ciências Sociais Aplicadas. Disponível em: < http://www.nucsa.unir.br>. Acesso em 26 de ab. 2019.

Fundação Universidade Federal de Rondônia (UNIR). Departamento de administração. Disponível em: 〈http://www.departamentoadm.unir.br〉. Acesso em 28 de mai. 2019.

FLEURY, M.T.L; OLIVEIRA JR, M.M.(Org.) Gestão estratégica do conhecimento: integrando aprendizagem, conhecimento e competências. São Paulo: Atlas, 2001. p. $15-49$.

GIL, Antônio Carlos, Métodos e técnicas de pesquisa social / Antônio Carlos Gil. - 6. ed. - São Paulo: Atlas, 2008.

HENDRIKSEN, E. S.; VAN BREDA, M. F. Teoria da Contabilidade. São Paulo: Atlas, 1999.

HERNANDES, D. C. R.; PELEIAS, I. R.; BARBALHO, V. F. O professor de Contabilidade: habilidades e competências. In: PELEIAS, Ivam Ricardo (Org.). Didática do ensino da contabilidade: aplicável a outros cursos superiores. São Paulo: Saraiva, 2006. p. 61-119.

IUDÍCIBUS, S. et. al.. Manual de contabilidade societária. São Paulo: Atlas, 2010.

IUDICIBUS, S.; MARION, J. C. Curso de contabilidade para não contadores. 4. ed. São Paulo: Atlas, 2008.

IUDÍCIBUS, S. et al. Contabilidade introdutória. 11. ed. São Paulo: Atlas, 2010. (o4.04)

LIMA, Ariovaldo Alves. Contabilidade básica. São Paulo: Atlas, 2006.

MARION, J. C. Contabilidade empresarial. 13. ed. São Paulo: Atlas, 2007. (04.04)

MARION, J. C. Curso de Contabilidade para não contadores: para as áreas de Administração, Economia, Direito e Engenharia. 4. ed. São Paulo: Atlas, 2008.

MOLINA, F. S. Metodologia do Ensino da Contabilidade Geral: algumas considerações. Revista Brasileira de Contabilidade, Brasília, v. 30, n. 129, mai.-jun. 2001, p. 93-97

PROBST, Gilbert; RAUB, Steffen; ROMHARDT, Kai. Gestão do conhecimento: os elementos construtivos do sucesso. Porto Alegre: Bookman, 2002

RAUPP, F. M.; BEUREN, I. M. Metodologia da pesquisa aplicável as ciências sociais. In: BEUREN, I. M. (Org.) Como elaborar trabalhos monográficos em contabilidade. 3. ed. São Paulo: Atlas, 2009.

SÁ, A. L. de. História geral e das doutrinas da contabilidade. São Paulo: Atlas, 1997. 
SCHMIDT, Paulo. Uma contribuição ao estudo da história do pensamento contábil. 1996. 1996. Tese de Doutorado. Dissertação (Doutorado), Faculdade de Economia, Administração e Contabilidade, USP.

SCHMIDT, P. História do pensamento contábil. Porto Alegre: Bookman, 2000.

SILVA, PYC da; PIRES, J. S. D. B. Investigação e análise da produção científica em contabilidade e sociedade no Brasil nos últimos 20 anos. Anais do Encontro Internacional de Produção Científica CESUMAR, Maringá, PR, v. 6, 2009. (04.04).

TEIXEIRA FILHO, J. Gerenciando conhecimento. Rio de Janeiro: Ed. Senac, 2000. $191 \mathrm{p}$

WIIG, K. M. Knowledge management foundations: thinking about thinking - How People and Organizations Create, Represent, and use Knowledge. Arlington: Schema, 1993. v. 1.

ZGAIB, A. O. Didáctica de la contabilidad. La pared. FACES, v. 13, n. 29, p. 35-62, 2007.p

Recebido em: 10/10/2021

Aprovado em: 05/11/2021

Publicado em: 10/11/2021 